\title{
Science and journalism: friend or foe?
}

\author{
Cătălin Mosoia \\ Brief Press Ltd \\ 6 Anton Bacalbasa, bl. 31, sc. 1, et. 4, ap. 13, sector 4, Bucharest 041928, Romania \\ email: catalin.mosoia@gmail.com
}

\begin{abstract}
A journalist's view on science and journalism. The presentation is based on personal experience gained over the past few years as editor of the minute of science broadcasted at Radio Europa FM, Bucharest, Romania, and as editor and writer for the Romanian electronic science newspaper Ziarul stiintelor. Is it possible to have science with or without journalism? Who is waiting for whom, science or journalism? Is astronomy more attractive to the public than other disciplines? Can it be used as a growing factor for the public understanding of science?
\end{abstract}

Keywords. science communication, science journalism, IYA2009, astronomy, media

\section{Introduction}

As humans we are curious, we are eager to know more than yesterday, we want to have more answers than why's, we want to understand what is going around us. If it happens to have an answer to one of our questions then we say that we understand. Finally, knowledge makes us feeling OK. Maybe, this is one of the aims of us as human beings. Knowledge is related to progress and from a very simple perspective; it is a matter of having answers to some questions. Progress is a question that has an answer. That is why I have the feeling that questions and answers are very important to us as people interested in science, particularly in astronomy. Be it from the side of science or mass media. There are questions that for the moment do not have answers. They might be called questions in looking for answers. There are people who are looking for answers. If there are science questions, we call them scientists or researchers. In a way or another, each of us is looking for some answers. Questions and answers form the base of communication. "Knowledge is accelerating exponential, so science will be more fascinating" as one of the participants of this symposium told. For example, the following questions got answers, more or less understandable. Do polar bears get lonely?, Why don't penguins' feet freeze?, Does anything eat wasps?, What time is it at the North Pole?, There are more hours of daylight after noon than before it, particularly in the summer. Does this mean midday is in the wrong place?, If all the matter in the Universe was created in the Big Bang, and if the Universe is expanding since then, by what mechanism can two old galaxies collide? These questions were taken from the very popular Last word column of New Scientist, the weekly magazine, also online. Their answers are an example of good science communication. There are attractive, interesting, informative and with a high value for the educational process.

There is also another perspective of explaining things that happens such as why lions are not as big as elephants?, what is the colour of a chameleon that is looking into a mirror? or things that should bring scientific results in the near future such as, what exactly could Galileo see through his telescope? 
Science communication might be done through journalism; be it practiced inside newspapers, on radio and TV broadcastings, or websites. Again, we are having a question to answer: Is it possible to have science without journalism? Maybe the answer is another question, such as Is it possible to have journalism without science? Otherwise, who is waiting for who, science or journalism? The beauty of astronomy makes it very attractive to the public. The public find out by the means of media. In astronomy are involved specialists with different backgrounds so astronomy might be seen as the locomotive of science. There are good and bad examples. I do not want to mention the good ones for the reason that it would make us feel happy and it is not the real true. Generally speaking, science subjects inside a news bulletin are left at the end. And this might be the happiest scenario. What happen when it is really covered? For example, LHC got a lot of media attention -people were asking so many questions about what is going to happen there. There were also people who warn scientists: You are trying to play the game of God! Give up! Media LHC coverage existed. Even if it was bad written, bad spoken, bad read, at the end a good thing happened: it attracts the world attention to science!

Solutions? How to determine the audience to look for science subjects? Let us offer what they are looking: information from medicine, telemedicine, news about gadgets, different tools that makes the daily life easy, origins of life on Earth, debates on very sensitive tasks such as the dialogue between science and religion. Almost all have at least one correspondent with space science. If there aren't we have to find it. I have the feeling that IYA2009 might be the right time for reinforcing science communication all over the world. Taking a short step back into the history we have to remind Bertrand Russell who received the Nobel Prize for literature in 1950. "Those who can act effectively as liaison officers between technical scientists and the public perform a work which is necessary, not only for human welfare, but even for bare survival of the human race." $\dagger$

Coming back to the present, there are ways that might be of help in science communicating. Practically speaking, the very first step consists of identification of the scientists who are interested in science communication. They might write about their activity or their area of competence in science. They can comment science news and this should do very often. Simultaneously, of great importance is the identification of science journalists and their area of competence. Be it from radio and TV, newspapers, electronic publications or blogs. At the same level of importance is to strengthen the relationship between scientists and journalists by bringing them together more often with different occasions. This is one of the aims of the bilingual (Romanian, English) electronic publication called "Science newspaper" (http://www.sciencenewspaper.eu) that was recently launched at the Association for Science Education 2009 annual conference, University of Reading, UK. It is a platform that gives the possibility to do communication through science journalism. It gives the opportunity to anybody interested in science and writing to publish, in certain conditions, their first article. It is dedicated to news from all branches of science with the aim of reinforcing science journalism. There are sections for news, open articles, and children with a view to build the new generation of science communicators.

The second step suggestion consists of training courses for both journalists as well as for scientists. How to write about science, science writing hands-on labs, the importance of the message in science communication, how to transmit the message with maximum of efficiency. In addition, practice.

$\dagger$ Extract from text of the address delivered by Bertrand Russell on receiving the Kalinga Prize at UNESCO on January 28, 1958. 
The CAPjournal (http: //www . capjournal.org) is a free peer-reviewed journal for astronomy communicators, online and in print. Taking into account the perspective of this presentation the publication is like the beam of hope. One of the greatest initiatives of the recent years in science communicating is the internationalising by the British Council of the Famelab competition (http://www. famelab.org). Finalists already formed a network, Beautiful Science Network, that has launched the Istanbul international declaration. Here there is a fragment: "We need governments and businesses to support and invest more in science communication. We urge educational establishments and the media to embrace the Beautiful Science approach. We ask these bodies to come together and do everything they can to encourage the energy, talent and enthusiasm of this new generation of science communicators" $\dagger$.

For the interested media persons there is also the European Initiative for Science Communicators (EICOS) Fellowships for journalists. It is organised by Max Planck Institute for Biophysical Chemistry in Göttingen, Germany, and it is a very useful for people interested in science writing (see http://www.eicos.mpg.de). Europa FM, the first private radio with national coverage from Romania, is broadcasting daily one minute of science. It might be listened at 12:00 and 17:00 hours inside the news bulletin (http://www.europafm.ro). Briefly mentioning the Science Newspaper, the electronic publication consists of news from all branches of science. There are also reports from science journalists, science educators, science communicators, scientists and teachers. Science is a universal language. Why can't the science newspaper be the same? How can we understand science if we are not speaking about science? There is another strong desire to promote people who are doing science. Ziarul Stiintelor (The Science Newspaper, http://www.ziarulstiintelor.eu) aims at promoting science education through journalism and create the next generation of science journalists. Also, it is acting as a platform for school pupils to submit their articles to, as part of enhancing their skills and learning about the world of science communication and the way scientists work. Children can submit their content to and be the authors of what they can read, giving them an opportunity to experience being a real science writer and a real science journalist.

We all know that nothing can be done alone. No human is an island. Science communication through journalism is not an exception. We have to collaborate; we have to change ideas with a view to improve the perception of science by the audience. In fact, we are speaking about progress and well-being of each of us.

$\dagger$ Beautiful Science Network International Declaration: We, young scientists and science communicators have been enthused by a passion for communicating the excitement and profound importance of science. We have been brought together by the British Council's Beautiful Science project and are now forming the Beautiful Science Network to foster a deeper and wider appreciation of science for the benefit of the global community. Science plays a vital rôle in every aspect of life but we feel that it is often misunderstood and undervalued. We are committed to ensuring the future of science for society with direct benefits to the economy, democracy and the enrichment of our culture. We are dedicated to science in education to inspire and encourage more people to take up science as a career. We aim to enable wider and more informed participation in political decision making, improve open dialogue between the public and the scientific community to encourage mutual trust and understanding, and to celebrate science as the expression of human curiosity and wonder. To this end, we aim to build a global sustainable network of science communicators. We need governments and businesses to support and invest more in science communication. We urge educational establishments and the media to embrace the Beautiful Science approach. We ask these bodies to come together and do everything they can to encourage the energy, talent and enthusiasm of this new generation of science communicators. Signed by members of the Beautiful Science Network from Austria, Azerbaijan, Bulgaria, Croatia, Greece, Israel, Romania, Serbia, Turkey and the UK, in Istanbul, 24 October 2008. 